\title{
Cyanobacterial Incident Management Frameworks (CIMFs) for application by drinking water suppliers
}

\author{
Hein du Preez ${ }^{1,2 *}$, Annelie Swanepoel ${ }^{1}$, Leoni van Baalen ${ }^{1}$ and A Oldewage ${ }^{2}$ \\ ${ }^{1}$ Analytical Services, Hydrobiology Section, Barrage Road, PO Box 3526, Vereeniging, South Africa \\ ${ }^{2}$ Department of Zoology, University of Johannesburg, PO Box 524, Auckland Park 2006, South Africa
}

\begin{abstract}
Cyanobacteria are commonly found in freshwater systems that are the source waters for the production of drinking water. This is of special importance to the drinking water suppliers as several genera of cyanobacteria can produce cyanotoxins that can affect human health. The possibility that drinking water can be a cyanobacterial-exposure route has resulted in the development of Cyanobacterial Incident Frameworks (CIMFs) that will guide water treatment managers to deal pro-actively with cyanobacteria and their associated toxins in source water by using a step-by-step alert levels framework to ensure provision of safe drinking water. In this paper two CIMF models are described, namely a CIMF model using cyanobacteria identification and enumeration as a primary trigger; and a CIMF model using chlorophyll $a$ as primary trigger. These frameworks are based on the same principle, but differ in minor actions taken, especially at the lower alert levels. It is envisaged that the developed CIMFs would be the platform on which to evaluate the capacity to manage a cyanobacterial incident. Based on the requirements stipulated in the CIMFs and their assessment, the drinking water treatment works (DWTW) would then develop and implement their customised CIMFs.
\end{abstract}

Keywords: cyanobacteria, Cyanobacterial Incident Management Framework (CIMF), drinking water, drinking water treatment works (DWTW), alert levels

\section{Introduction}

Cyanobacteria (blue-green algae) are a natural part of the phytoplankton populations of many surface freshwater bodies. The occurrence of cyanobacteria in freshwater is of special importance to the drinking water suppliers as several genera of cyanobacteria can produce offensive taste and odour compounds, as well as cyanotoxins that can affect human health. The cyanotoxins produced by many of the cyanobacteria (e.g. Microcystis, Anabaena, Planktothrix, Oscillatoria, Cylindrospermopsis and Nodularia) are a diverse group of chemical compounds, which can broadly be grouped into cyclic peptides, alkaloids and lipo-polysaccharides (Chorus and Bartram, 1999; Chorus, 2001; WHO, 2004, Cox et al., 2005; Falconer, 2005). Cyanotoxins can occur within the cyanobacterial cells (intracellular) or may be released into the surrounding water (extracellular) and therefore, drinking water treatment works (DWTW) should be able to deal with both forms of cyanotoxins (European Commission, 2005). The many reported mammalian health effects (Table 1) of these cyanotoxins, range from being neurotoxic (e.g. anatoxins, saxitoxins and beta-methylamino L-Alanine) or hepatotoxic (e.g. microcystins and nodularin) to inflammatory or irritants (e.g. lipopolysaccharide endotoxins) as well as having several combined effects (e.g. cylindrospermopsin). However, only a few suspected human poisonings are recorded, probably due to the fact that people avoid drinking offensive-smelling water and, more importantly, the common symptoms of cyanotoxin poisoning (vomiting, diarrhoea, stomach pains and head-

\footnotetext{
$*$ To whom all correspondence should be addressed.

前 +2716 430 8826; fax: +2716 455 2055;

e-mail: hdupreez@randwater.co.za

Received 9 February 2007; accepted in revised form 31 July 2007.
}

aches) are also the symptoms of gastrointestinal illness caused by bacterial, viral and protozoan infection, and are thus not linked to cyanotoxin poisoning (Falconer, 2005).

The possibility that humans may be exposed to cyanotoxins by ingesting contaminated water has resulted in the development of drinking water guidelines and investigations into the effectiveness of the removal of cyanobacteria and cyanotoxins during the drinking water treatment process. These developments prompted many drinking water utilities throughout the world to adopt the World Health Organization (WHO) provisional guideline for microcystin-LR (microcystin-LR $1 \mu \mathrm{g} / \ell$ ) or the derived guidelines based on their general approach. To date, guideline levels or concentration standards for microcystins have been incorporated into the national drinking water supply regulations in Australia, New Zealand, Brazil, Canada and the European Union (Falconer, 2005). In South Africa, water utilities have to produce water of acceptable quality as stipulated by the South African National Standard: Drinking Water (SANS, 2006). However, the standard does not require any monitoring of cyanotoxins in drinking water. This is a major shortcoming of the South African National Standard as many of the South African freshwater bodies that supply the drinking water treatments plants contain cyanobacteria, for example Microcystis, Anabaena, Oscillatoria and Cylindrospermopsis spp. (Van Ginkel and Conradie, 2001).

Drinking water utilities can implement various actions, e.g.:

- Optimising the extraction of source water

- Optimising the conventional treatment processes

- Implementing advanced treatment processes to reduce the risk of exposing consumers to cyanotoxins (see Fig. 1).

However, in practice, drinking water treatment managers have found it difficult to implement these actions in a coordinated 


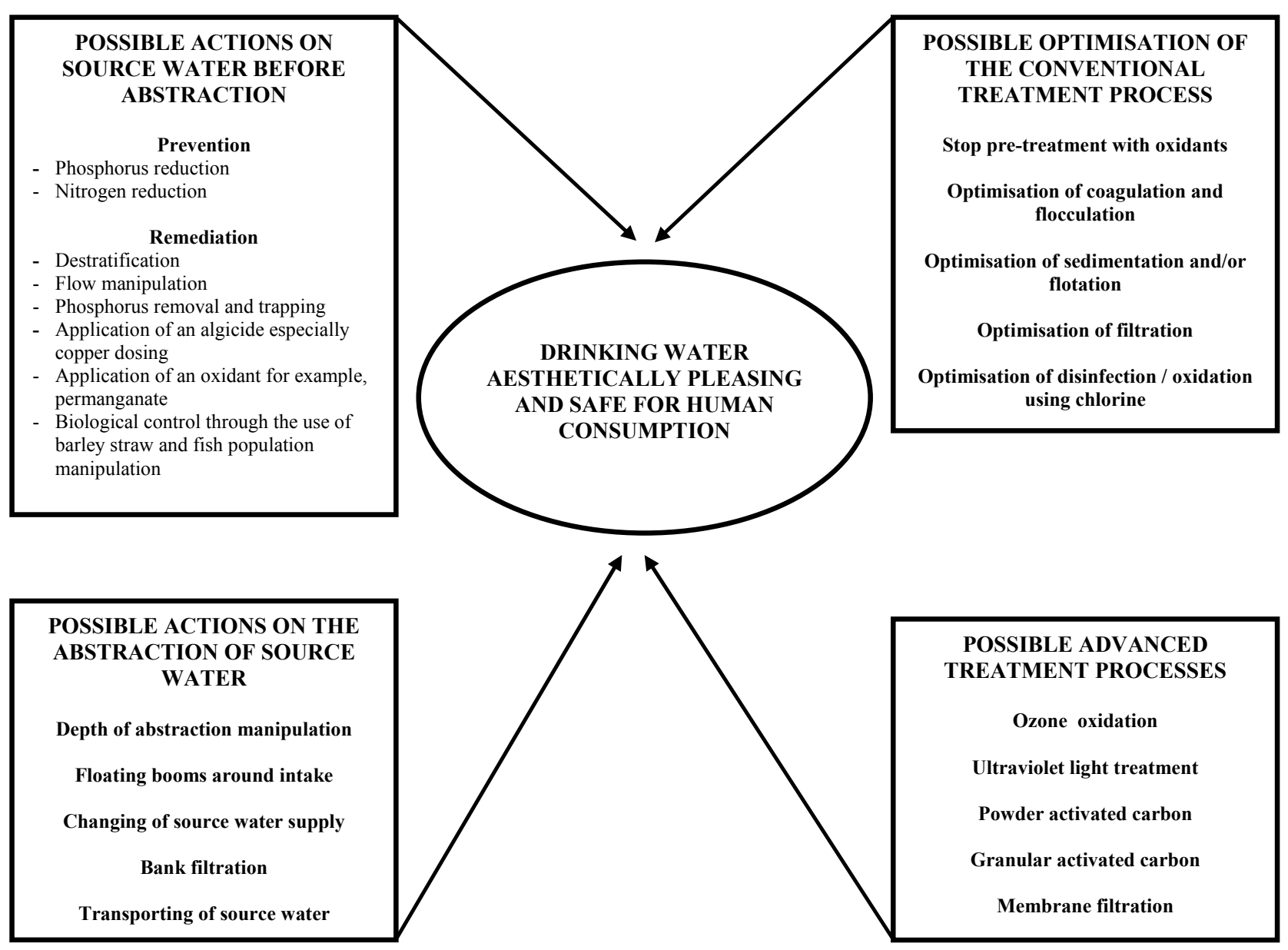

Figure 1

Actions that can be taken to reduce the risk of cyanobacterial effects on drinking water production (Chorus and Bartram, 1999; Newcombe, 2002; AWWA, 2004; Falconer, 2005; MWH, 2005)

manner. The development of Cyanobacterial Incident Management Framework (CIMF) models bridges this gap and guides water treatment managers to deal pro-actively with cyanobacteria and their associated toxins in source water by using a stepby-step alert levels framework to ensure the provision of safe drinking water to the consumer.

\section{Developments in CIMF application}

\section{The Burch model}

The Burch model (Burch, 1993) was developed for cyanobacteria-rich water resources in water resources in Australia and was based on cyanobacteria cell numbers in the source water that are set as triggers linked to a routine monitoring programme and three alert levels. Alert Level 1 is triggered when low numbers (500 to 2000 cells $/ \mathrm{m} \ell$ ) are detected in the source water; Alert Level 2 when there are moderate numbers (2000 to 15000 cells $/ \mathrm{m} \ell$ ) and Level 3 when there are persistently high numbers ( $>15000$ cells $/ \mathrm{m} \ell$ ), which are toxic. During the Alert Level 1 and Alert Level 2 phases the water supply is considered to be of acceptable quality, but at Alert Level 3 it is considered to be unsafe. The Burch model is further useful to drinking water utilities as it also describes some operational actions (e.g. altering off-take depth, the deployment of booms, the use of PAC, etc.) that could be undertaken, the analyses (e.g. cyanobacteria identification, cyanotoxins analyses) and the consultation (e.g. with the health authorities) that should be undertaken.

Burch's model of 1993 was further developed to form part of a national protocol for the monitoring of cyanobacteria and their toxins in surface freshwaters for use in Australia. This protocol is thorough and includes information on cyanobacteria, their toxins, sampling procedures, analyses procedures (cyanobacteria and toxin analyses) and alert levels frameworks for drinking water supply. The alert levels framework primarily uses the cyanobacterial biomass as trigger between the alert levels, ranging from a detection level (cyanobacteria $>500$ cells/ $\mathrm{m} \ell$ ), to Alert Level 1 (cyanobacteria $>2000$ cells $/ \mathrm{m} \ell$ ), to Alert Level 2 (cyanobacteria $>5000$ cells $/ \mathrm{m} \ell$ ) and finally to Alert Level 3 (cyanobacteria $>50000$ cells $/ \mathrm{m} \ell$ ).

\section{The World Health Organisation (WHO) model}

The alert levels framework for cyanobacteria proposed by the WHO (in Chorus and Bartram, 1999) is very similar to the Burch 1993 model. The WHO model is also triggered by different cyanobacteria concentrations in the source water, which are then translated into a vigilance level, an Alert Level 1 and an Alert Level 2, with appropriate actions and responses. The vigilance level is activated when cyanobacteria are detected at low concentrations and during this level the main actions would include an increase in monitoring and inspection of the source water at the intakes. 
The Van Baalen \& Du Preez Model (a Cyanobacterial Incident Management Framework (CIMF) Model for Drinking Water Utilities) proposed in 2001 (Van Baalen and Du Preez, 2001) is based on the principles of the Burch and WHO models, but adding additional criteria (e.g. cyanotoxin concentration in the final treated water) to make it more practical for day-to-day application by drinking water treatment managers. The Van Baalen and Du Preez CIMF model comprises various action levels, namely: Routine monitoring $\leftrightarrow$ Vigilance Level $\leftrightarrow$ Alert Level $1 \leftrightarrow$ Alert Level $2 \leftrightarrow$ Alert Level 3. Between each action alert there are primary triggers (phytoplankton identification and enumeration), secondary triggers (cyanotoxin concentration) and tertiary triggers (mouse bioassay test results), which allow for 'movement' (step-up or step-down) between the action alerts. As in the Burch and WHO models, each alert level describes the monitoring and actions that should be considered and undertaken by the drinking water treatment managers and the drinking water utilities at large. The advantage of adding cyanotoxin concentration in the final water as a secondary trigger is that a drinking water supplier is continuously aware of the potential risk posed by the cyanobacteria cells in the source water and the actual or current risk (in terms of toxin concentration) of the final drinking water. With this approach the operational changes can be implemented more appropriately thereby saving costs.

\section{Enhancements in CIMF application}

In this paper two CIMF models are described, namely:

- A CIMF model using cyanobacteria identification and enumeration as primary trigger

- A CIMF model using chlorophyll $a$ as primary trigger.

These frameworks are based on the same principle, but differ in minor actions taken, especially at the lower alert levels. The need for the CIMF model based on chlorophyll $a$ is that the drinking water suppliers (especially in South Africa) differ significantly in their capacity (i.e. amount of funding, type of infrastructure, skills and know-how, capacity available to perform operational tasks) to monitor and deal with cyanobacteria and cyanotoxins. It must, however, be stressed that the CIMF model based on chlorophyll $a$ is not as specific as the phytoplankton CIMF model and acts more as a screening tool for the source water and should be diligently used in conjunction with the results of the more detailed investigations as indicated in the chlorophyll $a$ CIMF model.

\section{Cyanobacterial incident management framework (CIMF) using cyanobacteria as primary trigger}

This CIMF model comprises various stages of action alerts, namely: Routine Monitoring $\leftrightarrow$ Vigilance Level $\leftrightarrow$ Alert Level $1 \leftrightarrow$ Alert Level $2 \leftrightarrow$ Alert Level 3 (Fig. 2). Between the Routine Monitoring Level and each action alert there are the primary (cyanobacterial identification and enumeration), secondary (cyanotoxin concentration) and tertiary (mouse test bioassay) triggers, which activate the next level and which allow for 'movement' (step-up or step-down) between the Routine Monitoring Level and the action alerts.

\section{Routine Monitoring Level (see Fig. 2)}

Routine monitoring refers to monitoring of the variable chosen as the primary trigger for a specific drinking water supplier as well as visual inspection of the intake water. The variable selected for this CIMF model is cyanobacterial identification and enumeration analysis, which is performed on the source water sample from the abstraction point at least once every 2 weeks. When a drinking water treatment works is prone to experiencing cyanobacterial/algal related problems, or has a history of problems experienced during summer and autumn months in their source water, it is recommended that cyanobacterial identification and enumeration analysis is included in their routine source water monitoring program. Guidelines on sample-taking, handling, storage, etc., can be found in the publications by DWAF (2002) and in Meriluoto and Codd (2005).

\section{Analyses}

Cyanobacterial identification and enumeration should be performed on the source water at least once every 2 weeks. It would be an advantage if this were performed more frequently.

\section{Stepping up activation}

When cyanobacteria are detected during the routine cyanobacterial analysis then the alert actions are stepped up to the Vigilance Level

\section{Vigilance Level (see Fig. 2)}

\section{Regular surveillance of source water}

The reservoir (dam), lake or river from which the source water is abstracted should be surveyed for the development of colour and scum associated with a cyanobacterial bloom (excessive cyanobacterial growth). This process may be aided by information on the typical seasonal and/or daily wind patterns and checking downwind shorelines for scum aggregation. The first site that should be examined is the area around the abstraction point. When a reservoir or lake is used by a DWTW as source, it is a good practice to survey different areas in and around the dam (not just the abstraction area) for cyanobacterial bloom development. Areas close to the shore are usually good places to detect increased algal growth because of the concentration effect in shallow waters. The reason for visual inspection for scum development in other areas of a reservoir is that many cyanobacteria concentrate in the surface layers of the water and can quite easily be transported from one location in a dam to another by the wind. Therefore, even though cyanobacteria may not be spotted at the abstraction point, this situation can easily change over a short period of time (within hours) by a change in wind direction, whereby a bloom present in another area of the dam may concentrate in the abstraction area. The visual inspection for the abstraction points and the reservoir should be undertaken at least monthly but preferably at least every 2 weeks.

When abstracting water from a river it is usually difficult to detect the development of a cyanobacterial bloom because the flow of most rivers restricts bloom development at one locality. Instead, the bloom develops as the water moves downstream and then appears at an abstraction point for a short period (pulse or plug flow). In some slow-flowing rivers frequent monitoring supports detection of an increase in cyanobacterial concentrations over time. When a river has weirs or naturally impounded areas, it is more likely that cyanobacterial and algal problems will occur there (if they are going to occur at all).

All stakeholders involved in the abstraction of water along a certain river or water source (e.g. DWTWs, government authorities and local communities) should preferably establish a net- 
work or forum to aid in the surveillance of and communication on the development and locality of cyanobacterial blooms. Such networks or forums will provide a platform where upstream users may notify downstream users about 'pockets' of high cyanobacterial concentrations moving downstream. It is important to note that the successful implementation of such a network/forum will depend on the selection of a central coordinator to drive the entire process.

\section{Analysis}

Cyanobacteria identification and enumeration should be performed at least once a week on the source water.

\section{Stepping up activation}

When the cyanobacteria concentration of the source water exceeds 2000 cells $/ \mathrm{m} \ell$ then the alert actions must be stepped up to Alert Level 1.

\section{Stepping down activation}

When cyanobacteria are not detected for 14 consecutive days during the routine cyanobacterial analysis of the source water then the alert actions are stepped down to the Routine Monitoring Level.

\section{Alert Level 1 (see Fig. 2)}

\section{Regular surveillance of source water}

Increase the surveillance (as described in section under Vigilance Level) of the reservoir (dam), lake or river from where the source water is abstracted to at least once a week for the development of colour and scum associated with a cyanobacterial bloom (excessive cyanobacterial growth). Visual inspection of the abstraction points for the development of colour and scums should be done weekly but preferably more frequently.

\section{Analysis}

Cyanobacterial identification and enumeration analysis must be performed daily on the source water at the abstraction point.

\section{Cyanotoxin screening/analysis}

Cyanotoxin screening refers to the determination of cyanotoxin (Table 1) concentrations by using either the ELISA or HPLC techniques (Meriluoto and Codd, 2005). It is important to perform a cyanotoxin analysis (the more comprehensive, the better, as appropriate management is more effective when the data are more representative) on the source and the final water. Cyanotoxin screening results from the source water will indicate if there are any cyanotoxins present and the screening results of the final water will be an indication of how well the process performs in removing these toxins (if at all) and also indicate the potential risk to the consumer.

The frequency of analysis should be at least once a week. If the drinking water utility does not have the capacity to perform cyanotoxin analysis, it is important to outsource the samples to laboratories that have that capacity.

\section{Mouse test bioassay}

Mouse test bioassays are performed to establish whether a water sample has any toxic effects on a mouse. This effect is then translated to the effect that the water sample may have when consumed by humans. A mouse test bioassay should be performed on the drinking water during cyanobacterial dominance in the source water. Should the dominant cyanobacteria species in the source water change over time then it is important to run the mouse test bioassay again to confirm that no other cyanotoxins are present.

\section{Notification to drinking water treatment works (DWTW)}

The manner in which the 'Notification to DWTW' will be executed will be proactively defined by the Response Committee (see Fig. 3). The notification should be documented, traceable and ideally should include the following:

- Background information including historical data related to previous incidents

- Current trends in the relevant water quality data related to the specific DWTW

\begin{tabular}{|c|c|c|}
\hline $\begin{array}{l}\text { Summary of cya } \\
\text { clinical symptom }\end{array}$ & $\begin{array}{r}\text { otoxins, and the cyanobact } \\
\text { of cyanotoxin exposure (ac } \\
\text { and Jones, } 199\end{array}$ & $\begin{array}{l}\text { TABLE } 1 \\
\text { eria that produce them, as well as of the recorded mammalian } \\
\text { lapted from NHMRC, 2004; Chorus and Bartram, 1999; Sivonen } \\
\text { 9; Chorus, 2001; Falconer, 2005) }\end{array}$ \\
\hline Toxin & Cyanobacterial genera & Clinical symptoms \\
\hline Cyclic peptides & & \\
\hline Microcystins & $\begin{array}{l}\text { Microcystis, Anabaena, } \\
\text { Oscillatoria, Planktothrix, } \\
\text { Nostoc }\end{array}$ & $\begin{array}{l}\text { Gastro-enteritis, fever, pains in muscles and joints, nausea, vomiting, } \\
\text { blistering around mouth, diarrhoea, swollen liver, death by liver failure }\end{array}$ \\
\hline Nodularin & Nodularia & $\begin{array}{l}\text { Gastro-enteritis, fever, pains in muscles and joints, nausea, vomiting, } \\
\text { diarrhoea, swollen liver, death by liver failure }\end{array}$ \\
\hline Alkaloids & & \\
\hline Cylindrospermopsin & $\begin{array}{l}\text { Cylindrospermopsis, Aphani- } \\
\text { zomenon, Anabaena, Raphi- } \\
\text { diopsis, Umezakia }\end{array}$ & $\begin{array}{l}\text { Abdominal pains, vomiting, swollen liver, liver failure, pathological dam- } \\
\text { age to the kidneys, spleen, thymus and heart }\end{array}$ \\
\hline Anatoxin-a & $\begin{array}{l}\text { Anabaena, Planktothrix, } \\
\text { Oscillatoria, Aphanizomenon }\end{array}$ & $\begin{array}{l}\text { Muscle weakness, respirator distress, exaggerated abdominal breathing, } \\
\text { hyperactivity, hyper-salivation, numbness around the lips, paralysis }\end{array}$ \\
\hline Anatoxin-a(S) & Anabaena, Aphanizomenon & $\begin{array}{l}\text { Muscle weakness, respirator distress, exaggerated abdominal breathing, } \\
\text { hyperactivity, hyper-salivation, numbness around the lips, paralysis }\end{array}$ \\
\hline Saxitoxins & $\begin{array}{l}\text { Anabaena, Aphanizomenon, } \\
\text { Lyngbya, Cylindrospermopsis }\end{array}$ & $\begin{array}{l}\text { Numbness around the lips, complete paralysis, death from respiratory } \\
\text { failure }\end{array}$ \\
\hline Lipo & & \\
\hline Lipo-polysaccharides & All & Allergic reactions, inflammation, irritation, gastro-enteritis \\
\hline
\end{tabular}




\section{CYANOBACTERIAL INCIDENT MANAGEMENT FRAMEWORK - for use by potable water suppliers}

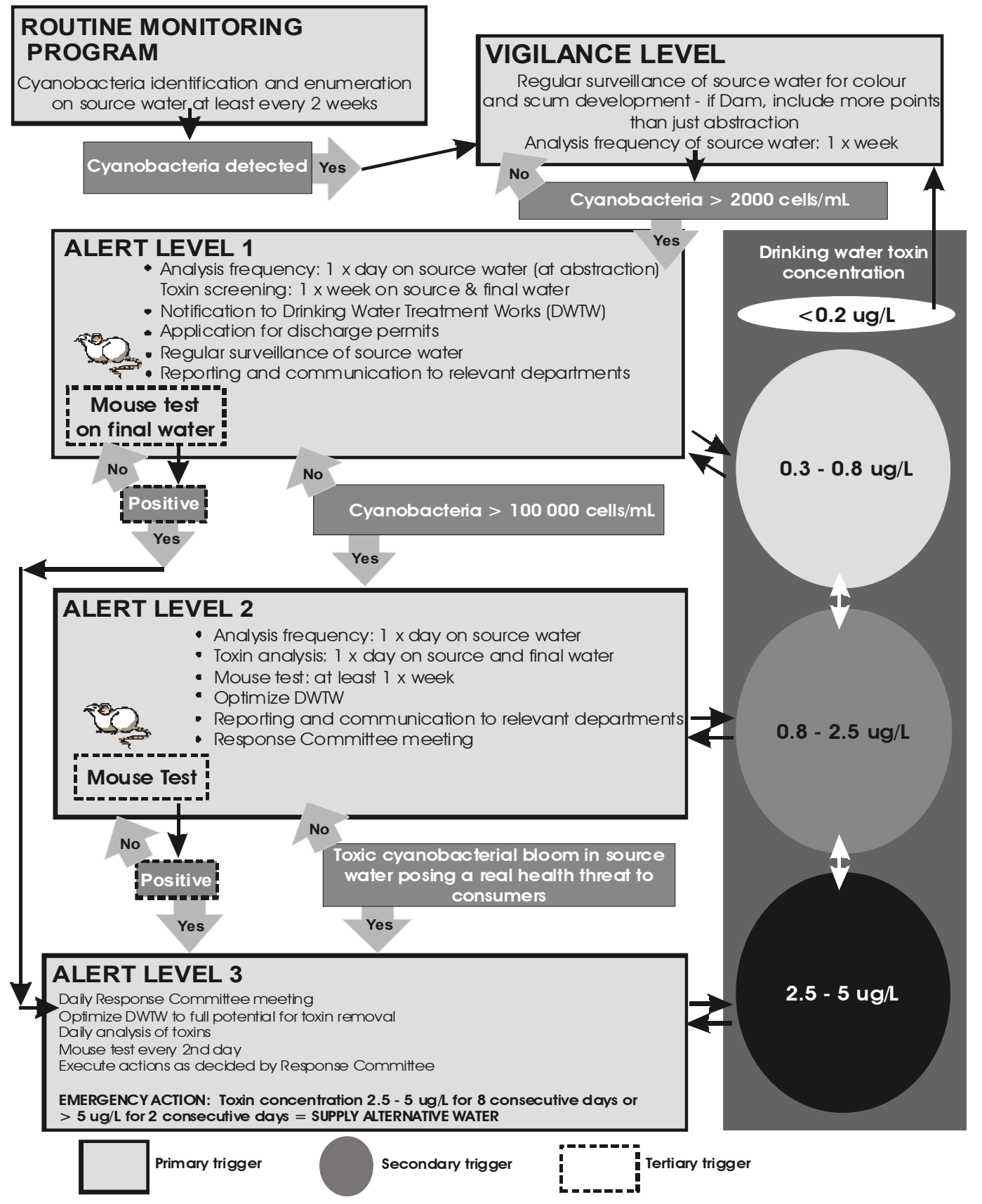

Figure 2

Cyanobacterial Incident Management Framework (CIMF) model using cyanobacterial concentrations as a primary trigger

- Prediction in terms of immediate and short-term possibilities of cyanobacterial bloom formation.

- Recommendations for possible actions (e.g. ensure sufficient coagulant is available; ensure that staff are aware and ready to react at short notice; ensure that all steps in the process can be optimised and are in working condition, etc.) that can be taken into consideration in order to prepare for a cyanobacterial incident (Fig. 1).

\section{Discharge permits}

Discharge permits from the government authorities are necessary for the discharge of any waste into natural water systems. Should a cyanotoxin incident occur, it is likely that a decision will be taken not to recycle filter backwash water back to the head of the drinking water treatment works, but to store the water on-site in storage dams or to discharge the filter backwash water into the river or reservoir/dam below the point of 
abstraction. No discharges are permitted without a valid permit. For more information it is recommended that the government authority in charge of the specific area be contacted for clarification on procedures and requirements. It is also recommended that the process of obtaining a discharge permit be initiated in a pro-active manner (e.g. when the CIMF or the Water Safety Plan is developed), as this can be a very lengthy process.

\section{Reporting and communication}

The communication and reporting that must be initiated will have been defined proactively by the Response Committee (see Fig. 3), which would in turn be determined by the size and the communication structures of the water utility. The Response Committee ensures that the role-players have a sound knowledge of the CIMF model and are familiar with their responsibilities, that the actions as stipulated in the CIMF model are implemented, that unforeseen problems/issues (technical; communication-related, etc.) are speedily addressed, that all the necessary data and information are available and shared between the role-players, that there is effective internal and external communication and that the CIMF model is updated as experience is gained. A typical Response Committee and their possible roles are presented in Fig. 2.

At Alert Level 1, there should already be some communication between the water quality coordinator, the specialist on cyanobacteria and drinking water treatment, the analytical laboratory staff and the drinking water treatment works manager (see Fig. 3).

\section{Stepping up activation}

When the cyanobacterial concentration in the source water exceeds 100000 cells $/ \mathrm{m} \ell$ then actions should be stepped up to Alert Level 2.

\section{OR}

When the cyanotoxin concentration in the drinking water exceeds $0.8 \mu \mathrm{g} / \ell$ then actions should be stepped up to Alert Level 2.

\section{OR}

When the mouse test bioassay is positive for cyanotoxins in the drinking water then actions should be stepped up to Alert Level 3.

\section{Stepping down activation}

When the cyanobacterial concentration in the source water decreases to below 2000 cells $/ \mathrm{m} \ell$ for at least 14 consecutive days, the cyanotoxin analysis concentration in the drinking water is $<0.2 \mu \mathrm{g} / \ell$ for 14 consecutive days and the mouse test bioassay is repeatedly negative for the drinking water then actions should be stepped down to the Vigilance Level.

\section{Note:}

When stepping up or down from one alert level to the next it is always important to use the primary trigger (in this CIMF: cyanobacterial concentrations in the source water) as default analysis to determine which actions to take. However, should the cyanotoxin concentration exceed the concentration limits of the alert level in which it is operating (based on the primary trigger) then the secondary trigger (cyanotoxin concentration) overrides the primary trigger and the actions should be performed at the alert level specified by the secondary trigger. Similarly, should the mouse test bioassay be positive, then the tertiary trigger (mouse test bioassay) overrides the primary trigger and the actions should be performed at the alert level specified by the tertiary trigger. Should the concentration of the secondary trigger decrease to lower alert levels (or should the tertiary trigger be repeatedly negative) then actions should revert back to the appropriate alert level as dictated by the results of the primary trigger.

\section{Alert Level 2 (see Fig. 2)}

\section{Regular surveillance of source water}

Increase the surveillance (see also section on Vigilance Level) of the reservoir/dam, lake or river from which the source water is abstracted. Visual inspection of the abstraction points for the development of colour and scums should be done daily while the reservoir should be inspected at least weekly but preferably more frequently.

\section{Analysis}

Cyanobacterial identification and enumeration analysis must be performed daily on the source water at the abstraction point.

\section{Cyanotoxin screening/analysis}

Cyanotoxin analysis is performed daily on the source water and the drinking water (also see section on Alert Level 1). If the drinking water utility does not have the capacity to perform cyanotoxin analyses it is important to outsource the samples to laboratories that have the requisite capacity.

\section{Mouse test bioassay}

Mouse test bioassay is performed at least once a week on the drinking water (also see Section at Alert Level 1).

\section{Optimisation of the drinking water treatment works (DWTW)}

The optimisations that should be considered fall into the following broad categories:

- Actions on the abstraction of the source water (e.g. manipulation of the depth of abstraction)

- Optimisation of the conventional treatment process (e.g. stop pre-treatment with oxidants, optimisation of coagulation, flocculation, sedimentation, filtration and flotation processes, optimisation of disinfection with chlorine)

- The use of advanced treatment processes (e.g. ozone, powdered activated carbon; see Fig. 1). It is recommended that the possible optimisation process that could be implemented is identified and tested in a pro-active manner during the development of the CIMF for the specific DWTW. If this has already been done the main focus would then be to ensure that the actions are implemented and are functioning optimally to ensure that the drinking water utility can effectively remove cyanobacteria and cyanotoxins from the source water as soon as the cyanobacterial concentrations increase. This will also reduce the probability of reaching Alert Level 3.

\section{Response Committee meeting}

A meeting of the Response Committee is convened as one of the actions at Alert Level 2. The structure, roles and responsibilities of each member of the Response Committee would have been defined pro-actively during the development of the CIMF for that specific DWTW. However, this would be dependent on the size and the communication structures of the Drinking Water Utility. At their first meeting it is important to familiarize each member with the CIMF model; to clarify their roles and responsibilities; and to update contact information. The Response Committee discusses the current situation based on the available data, determines the appropriate actions that must be taken 


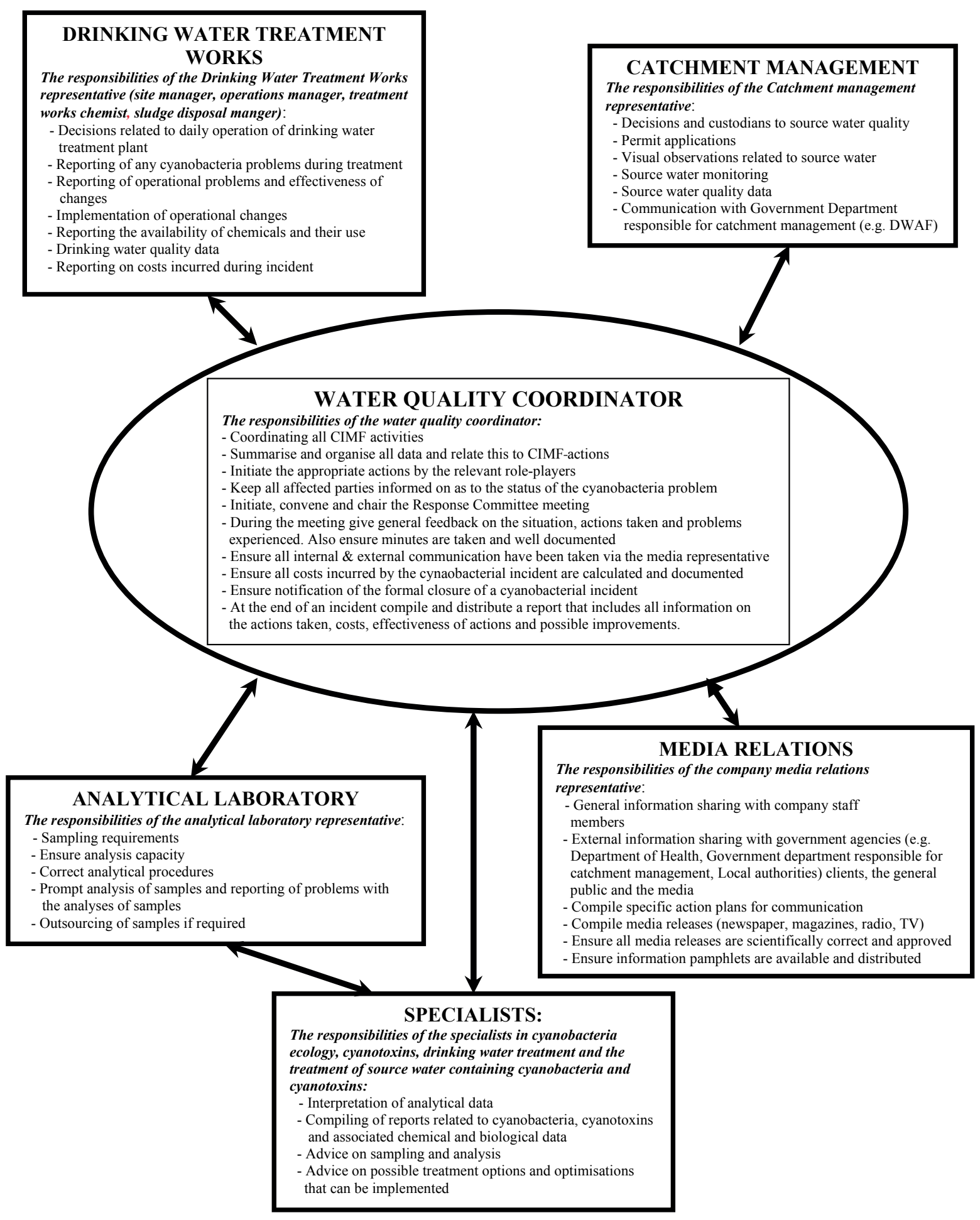

Figure 3

Possible communication channels and the possible roles of the representatives for a CIMF model

and identify any problems that may prevent the implementation of those actions. Dates for feedback and follow-up meetings are set. Formal minutes of the meeting are kept.

\section{Discharge permits}

If the discharge permit has not been received from the responsible government authority, the Response Committee decides on the course of action to obtain it (see comments at Alert Level 1).

\section{Reporting and communication}

The reporting and communication focus on internal reporting and communication to ensure that information is shared and any actions are speedily taken and implemented (see Fig. 3).

\section{Stepping up activation}

When the cyanobacterial concentrations in the source water consistently exceeds 100000 cells $/ \mathrm{m} \ell$, are toxic and cause scums to 


\section{CYANOBACTERIAL INCIDENT MANAGEMENT FRAMEWORK - for use by potable water suppliers}

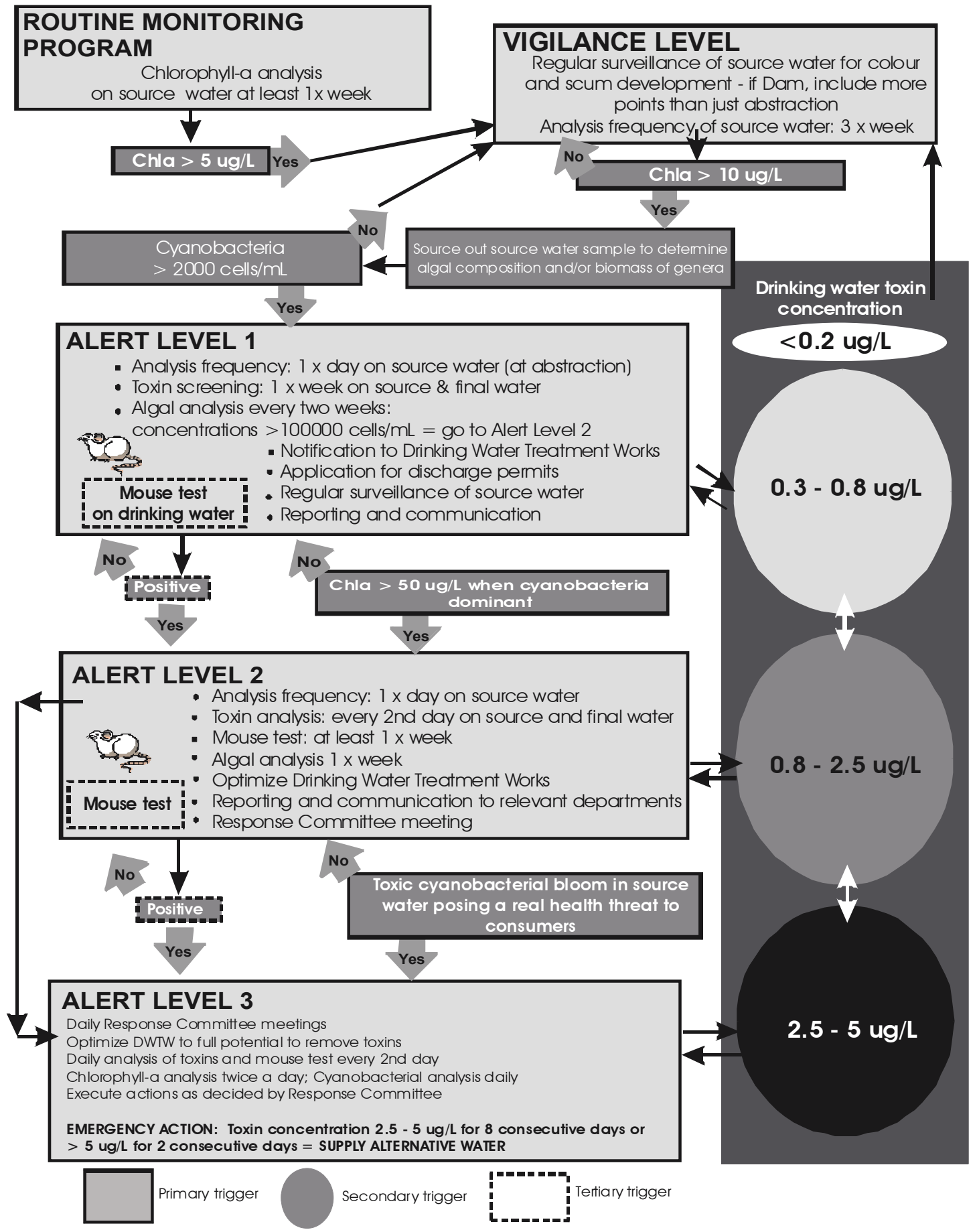

Figure 4

Cyanobacterial Incident Management Framework (CIMF) using chlorophyll a concentration as a primary trigger

form in the source water then actions should be stepped up to Alert Level 3.

\section{OR}

When the cyanotoxin concentration in the drinking water is between 0.8 and $2.5 \mu \mathrm{g} / \ell$ for more than 14 days then actions should be stepped up to Alert Level 3.
OR

When the cyanotoxin concentration in the drinking water exceeds $>2.5 \mu \mathrm{g} / \ell$ for more than 4 consecutive days then actions should be stepped up to Alert Level 3.

OR

When the mouse test bioassay is positive for cyanotoxins in 
the drinking water then actions should be stepped up to Alert Level 3.

\section{Stepping down activation}

When the cyanobacterial concentrations in the source water decrease to below 100000 cells $/ \mathrm{m} \ell$ for at least 14 consecutive days, the cyanotoxin concentration in the drinking water is $<0.8$ $\mu \mathrm{g} / \ell$ for 14 consecutive days and the mouse test bioassays are repeatedly negative for the drinking water, then actions should be stepped down to Alert Level 1.

\section{Alert Level 3 (see Fig. 2)}

\section{Regular surveillance of source water}

Surveillance (see also vigilance level) of the reservoir/dam, lake or river from which the source water is abstracted should be undertaken at least daily at the abstraction point and surrounding area for the development of colour and scum associated with a cyanobacteria bloom (excessive cyanobacteria growth).

\section{Analysis}

Cyanobacterial identification and enumeration analysis must be performed twice a day (early morning and late afternoon) on the source water at the abstraction point. A depth profile of the cyanobacterial cell concentrations in the source water column must be determined (e.g. when abstracting from a dam), and thereafter a series of profiles (at least 4) over a $24 \mathrm{~h}$ period must be performed to optimise the abstraction, as the cyanobacterial cell concentrations may show diurnal depth variation.

\section{Cyanotoxin screening/analysis}

Cyanotoxin analysis is performed daily on the source water and the drinking water (also see Section at Alert Level 1). If the drinking water utility does not have the capacity to perform cyanotoxin analyses it is important to outsource the samples to laboratories that have the requisite capacity.

\section{Mouse test bioassay}

Mouse test bioassay is performed on the drinking water at least every alternative day (also see Section at Alert Level 1).

\section{Optimisation of the drinking water treatment works}

The drinking water treatment works should be optimised to its full potential for cyanobacteria and cyanotoxin removal (see also section on Alert Level 1). The ultimate aim is to reduce the cyanotoxin concentration in the drinking water to less than $1 \mu \mathrm{g} / \ell$.

\section{Response Committee meeting}

The Response Committee should meet daily during Alert Level 3 to evaluate the success of measures implemented and to decide on further actions to be taken. Special attention should be given to solving optimisation problems that are being experienced, alternative actions that can be implemented and communication with external role-players (Department of Health, Department of Water Affairs and Forestry, customers and the general public). Formal minutes of the meetings are kept.

\section{Discharge permits}

If the discharge permit has not been received from the appropriate government authorities, the Response Committee should decide on the course of action to obtain this (see comments in section on Alert Level 1).

\section{Reporting and communication}

Reporting and communication focus on both internal (relevant role-players) and external role-players (Department of Health, Department of Water Affairs and Forestry, customers and the general public) to ensure that information is shared and any actions are speedily taken and implemented (see Fig. 1).

\section{Emergency action}

When the cyanotoxin concentration in the drinking water is between 2.5 and $5 \mu \mathrm{g} / \ell$ for more than $8 \mathrm{~d}$ then an alternative drinking water source must be supplied.

OR

When the cyanotoxin concentration in the drinking water exceeds $5 \mu \mathrm{g} / \ell$ for more than $2 \mathrm{~d}$ then an alternative drinking water source must be supplied.

\section{Stepping down activation}

When cyanobacterial scum formation in the source water is not evident for at least 14 consecutive days, the cyanotoxin concentration in the drinking water is less than $2.5 \mu \mathrm{g} / \ell$ for 14 consecutive days and the mouse test bioassays are repeatedly negative for the drinking water then actions should be stepped down to Alert Level 2.

\section{Closing procedure}

When the conditions as described for Alert Level 1 occur after a cyanobacterial incident, then the Response Committee should close the incident. This would include a formal report describing the incident, the actions that were taken and the recommendations for improvements to the CIMF as well as preventative actions. All role-players must receive the final communication of the closure of the incident.

\section{Cyanobacterial incident management framework (CIMF) using chlorophyll a as primary trigger}

This CIMF model also consists of various stages of action alerts, namely: Routine monitoring $\leftrightarrow$ Vigilance Level $\leftrightarrow$ Alert Level 1 $\leftrightarrow$ Alert Level $2 \leftrightarrow$ Alert Level 3 (Fig. 4). Between the Routine Monitoring Level and each action alert there are the primary (chlorophyll $a$ concentration), secondary (cyanotoxin concentration) and tertiary (mouse test bioassay) triggers, which activate the next level and allow for 'movement' (step-up or step-down) between the Routine Monitoring Level and the action alerts. It is thus important to note that this CIMF uses chlorophyll $a$ concentration as the primary trigger. However, in using the chlorophyll $a$ CIMF, there will be an increased risk of not detecting the cyanobacteria and their toxins at lower levels, compared to the cyanobacteria identification and enumeration CIMF model (Risk: chlorophyll $a$ CIMF model > cyanobacteria identification and enumeration CIMF model).

All the actions and activities of the CIMF model using the chlorophyll $a$ as primary trigger are similar to the CIMF model using cyanobacterial concentrations, the only exception being the initial monitoring of chlorophyll $a$ concentration as a primary trigger at the Routine Monitoring Level, the Vigilance Level, Alert Level 1 and Alert Level 2 (Fig. 4). When stepping up or down from one alert level to the next the chlorophyll $a$ concentration in the source water is used as the primary trigger. However, should the cyanotoxin concentration exceed the concentration limits of the alert level in which it is operating (based on chlorophyll $a$ concentration: primary trigger) then the secondary trigger (cyanotoxin concentration) overrides the primary 
trigger and the actions should be performed at the alert level specified by the secondary trigger. Similarly, should the mouse test bioassay be positive, then the tertiary trigger (mouse test bioassay) overrides the primary trigger and the actions should be performed at the alert level specified by the tertiary trigger. Should the concentration of the secondary trigger decrease to lower alert levels (or the tertiary trigger be repeatedly negative) then actions should revert back to the appropriate alert level as dictated by the results of the primary trigger.

\section{Conclusions}

Cyanobacteria in the source water can affect the drinking water treatment process (e.g. ineffective coagulation, flocculation and sedimentation, clogging of sand filters), as well as the quality (e.g. penetration of sand filters, the release of taste and odour compounds as well as toxic compounds) of water produced by the DWTWs. To assist drinking water treatment managers to meet these challenges several CIMF models have been developed; notably the Burch, WHO, and Van Baalen Models as well as the chlorophyll $a$ and the cyanobacteria identification and enumeration CIMFs presented in this study. It is envisaged that the developed CIMFs would be the platform on which to evaluate the capacity to manage any cyanobacterial incident. Based on the requirements stipulated in the CIMFs and their assessment, the drinking water utility would then develop and implement their customised CIMF model. This process would not only ensure that the drinking water utility has structures in place to deal with a cyanobacterial incident, but will also assist in improving the level of knowledge and understanding of cyanobacteria and cyanotoxins amongst the various role-players within the organisation.

\section{Acknowledgements}

The financial support received from the Water Research Commission and Rand Water to conduct this project is gratefully acknowledged. The authors wish to thank the members of the Steering Committee (WRC Project No. K5/1445/3) and individuals from many drinking water utilities in South Africa for their input as well as the Lower Orange River Remediation Forum (LORRF) for their valuable input during early versions of this paper, making it practical and useful to the water industry. The Rand Water Response Committee for cyanobacterial toxin management in drinking water, are also thanked for their years of input into developing Rand Water's framework, which formed the basis of this paper.

\section{References}

AMERICAN WATER WORKS ASSOCIATION (2004) Algae Detection and Removal Strategies for Drinking Water Treatment Plants. AWWA Research Foundation, 6666 West Quincy Avenue, Denver, CO 80235-3098 USA.466pp.

BURCH MD (1993) The development of alert levels and response framework for the management of blue-green algal blooms. In:
Proc. Blue-Green Algal Blooms - New Developments in Research and Management. A Symposium convened by the Australian Centre for Water Quality Research and the University of Adelaide on17 Feb.1993, Adelaide, S. Australia.

CHORUS I (ed.) (2001) Cyanotoxins: Occurrence, Causes, and Consequences. Springer-Verlag Berlin Heidelberg, Germany. 357 pp.

CHORUS I and BARTRAM J (eds.) (1999) Toxic Cyanobacteria in Water: A Guide to their Public Health Consequences, Monitoring and Management. E \& FN Spon, London, UK.

CHORUS I (2005) Current Approaches to Cyanotoxin Risk Assessment, Risk Management and Regulations in Different Countries. Federal Environmental Agency (Umweltbundesamt) P.O.B. 14 06, 06844 Dessau. 117 pp.

COX PA, BANACK SA, MURCH SJ, RASSMUSSEN U, TIEN G, BIDIGARE RR, METCALF JS, MORRISON LF, CODD GA, and BERMAN B (2005) Diverse Taxa of Cyanobacteria Produce BetaN-Methylamino-L-Alanine, a Neurotoxic Amino Acid. Published by the Nation Academy of Sciences of the USA. www.pnas.org/cgi/ doi/10.1073/pnas.0501526102

DEPARTMENT OF WATER AFFAIRS AND FORESTRY (2002) National Eutrophication Monitoring Programme, Implementation Manual. Compiled by Murray K, Du Preez M and Van Ginkel C, Pretoria, South Africa.

EUROPEAN COMMISSION (2005) Best Practice Guidance for Management of Cyanotoxins in Water Supplies. Part of the EU's $5^{\text {th }}$ Framework project: 'Barriers against Cyanotoxins in Drinking Water' (TOXIC’ EVK1-CT-2002-00107). 136 pp.

FALCONER IR (2005) Cyanobacterial Toxins of Drinking Water Supplies: Cylindrospermopsins and Microcystins. CRC Press, Florida, USA. 279 pp.

MERILUOTO J and CODD GA (2005) TOXIC. Cyanobacterial Monitoring and Cyanotoxin Analysis. ABO Akademis Forlag, ABO Akademi University Press, Tavastgatan 30C, FIN-20700 ABO, Finland. 149pp.

MWH (2005) Water Treatment: Principles and Design. ( $2^{\text {nd }}$ edn.) Revised by Crittenden JC, Trussell RR, Hand DW, Howe KJ and Tchobanoglous G. John Wiley \& Sons, Inc., New Jersey, USA. ISBN 0-471-11018-3. 1948 pp.

NEWCOMBE G (2002) Removal of Algal Toxins from Drinking Water Using Ozone and GAC. AWWA Research Foundation and American Water Works Association. 133 pp.

NATIONAL HEALTH AND MEDICAL RESEARCH COUNCIL (NHMRC) (1994) Health Effects of Toxic Cyanobacteria (bluegreen algae). Ressom R, Soong FS, Fitzgerald J, Turczynowicz L, El Saadi O, Roder D, Maynard T and Falconer I (eds.) Looking Glass Publishers. Australian Government Publishing Services. GPO Box 94, Canberra ACT 2601, Australia. 108 pp.

SIVONEN K and JONES (1999) Cyanobacterial toxins. In: Toxic Cyanobacteria in Water. Chorus I. \& Bartram J. (eds.) E \& FN Spon, London, 41-111.

STANDARDS SOUTH AFRICA (2006) South African National Standard: Drinking Water, SABS 241, 2006. Standards South Africa, Pretoria, Republic of South Africa.

VAN BAALEN L and DU PREEZ HH (2001) Incident Management Framework for Blue-Green Algal Toxins. Final Report April 2001. Rand Water, South Africa.

VAN GINKEL CE and CONRADIE BL (2001) Potential Toxic Algal Incident in the Orange River, Northern Cape, 2000. DWAF Report N/D801/12/DEQ/0800. Department of Water Affairs and Forestry, South Africa.

WORLD HEALTH ORGANIZATION (WHO) (2004) Guidelines for Drinking-Water Quality. ( ${ }^{\text {rd }}$ edn.) Volume 1 Recommendations. World Health Organization, Geneva. 515 pp. 